\title{
Relationship between depth and morphology of foraminifera in Abderaz Formation, IRAN
}

\author{
Meysam Shafiee Ardestani ${ }^{1 *}$, Masoud Asgharian rostami ${ }^{1}$, Behzad Balmaki ${ }^{2}$, Behnaz Balmaki \\ 1- Department of Geology, Faculty of Science, Ferdowsi University of Mashhad, Mashhad, Iran \\ 2- Department of Archaeology, Islamic Azad University Hamedan Branch, Hamedan, Iran \\ 3-Department of Geology, Faculty of Science, Payame Noor university of Tehran, Tehran, Iran \\ * Corresponding author: m_shafiee@khayam.ut.ac.ir (Meysam Shafiee Ardestani)
}

\begin{abstract}
Abderaz Formation at its type section with an age of Turonian-early Campanian and a thickness of $300 \mathrm{~m}$ contains light grey shale and marl. The study of the planktonic foraminifera in isolated form led to differentiate three morphotype groups. The first group is characterized by trochospiral tests usually indicate shallow waters, the second group contains forms with strong ornamentations and the primary keels representing mid waters and finally compact trochospiral tests with keels known as deep water indices are included in the third group. Studies on the morphotypes showed a regressive cycle for Abderaz Formation. In the present study the depth of Abderaz Formation was determined using planktonic morphotypes. As Results of the study all changes in test of planktons were observed in related to the water depth of their ecosystem. The data of the represented research are in confirmation with the Pascal Law.
\end{abstract}

Key words: Abderaz Formation, Planktonic foraminifera, ecosystem, Morphotype, Pascal Law

\section{Introduction}

The thing that is obvious in the evolution trend of planktonic foraminifers in (Hedbrgellids) From lower cretaceous till Gobotruncanids in the late cretaceous is that during their evolution from the outset shapes to advanced, this unicellular have a completely umbilicus part With a cover plate named tegilla ( Loeblich and Tappan, 1950). The main aim of this article is to know if the created trends of changing in shell of these animals made from the depth changing of the existence time of the animal shell because such as now a days that is proved, Hedbergella was in shallow depth and the shapes of their evolution had lived in more depth water compared to their ancestors (Fig1). Then 20 SEM images have been obtained and demonstrated in frame of 1

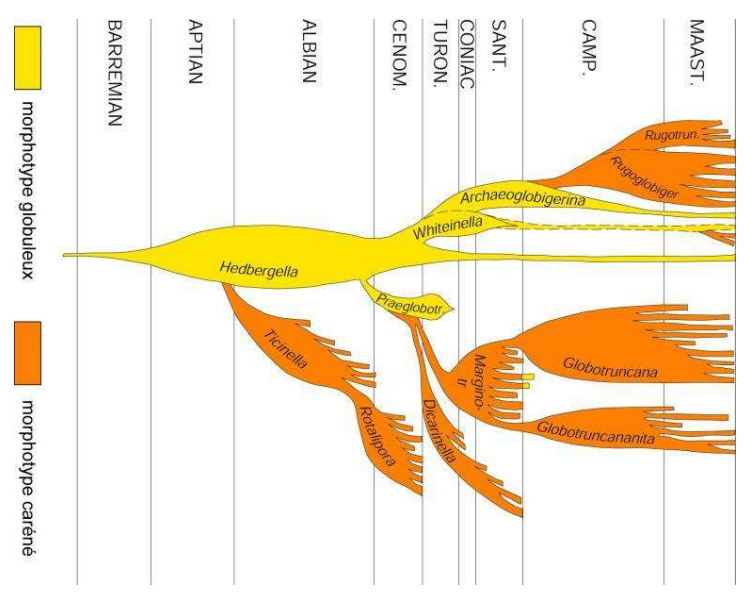

Fig1: Depiction of planktonic foraminifer's evolution (Caron and Homewood, 1983)

\section{Material and Method}

The section studied is located about $1 \mathrm{~km}$ to the Muzduran, north eastern Mashhad(a city of Iran), Kopet Dagh basin. At this locality (E: $60,{ }^{\circ} 33^{\prime}, 00^{\prime \prime}, \mathrm{N}: 36^{0}, 10^{\prime}, 40^{\prime \prime}$ )(Fig2). Type section of Abderaz Formation has $300 \mathrm{~m}$ thickness. At the typical gap such as all regions under the surface sub-contact of Abderaz Formation are un-correlated with Aitamir Formation. But its upper layer with Abtalkh Formation is in continuous correlation. The upper layer has elected as chalk limestone upper border. A total of 130 samples were collected from the section,but Only 102 samples were included in study, 7 samples due to the existence of salvation effects and 21 samples was obtained from reworking damages that were excluded from the study. which were soaked in water with diluted hydrogen peroxide, washed through $63 \mu \mathrm{m}, 150 \mu \mathrm{m}$ and $250 \mu \mathrm{m}$ sieves, and dried until clean foraminiferal residues were recovered. About 200-300 individuals were picked up for each sample in two size fractions $(63-150 \mu \mathrm{m}$ and $>150 \mu \mathrm{m})$ and mounted on dark cardboard slides for identification. These two size fractions were analyzed in order to obtain statistically significant representatives of the small and large groups Species identifications are based on(Caron, 1985, Robaszynski and Caron, 1983-1984, Loeblich and Tappan, 1988, Nederbragt, 1990 Robaszynski and Caron1995).

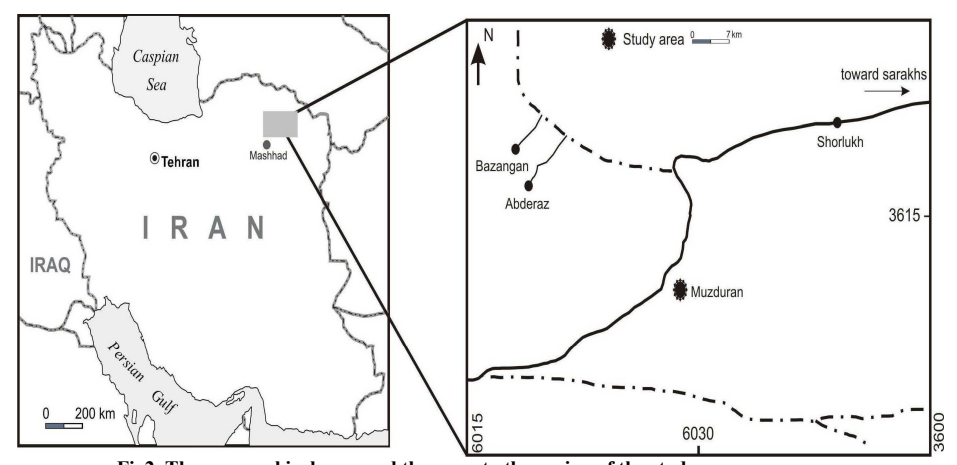

Fig2. The geographical map and the ways to the region of the study 
Groups of planktonic morphotyes are distinguished by depth of living (Hart, 1980a, Hart, 1980b, Wonders 1980, Keller, 1999) (Fig3). that are consist of:

\section{1- Shallow area faunas}

Heterohelix and Hedbergella and a big part of Hedbergella small samples likeGlobotruncanids genus are related to faunas of shallow epicontinental seas or the border sea (Eicher, 1969, Eicher and Worstell, 1970, Sliter 1972).

2- Middle water faunas

Praeglobotruncana and Whiteinella are related to this faunas

3- Deep water faunas (lower than 100)

These faunas were counted like keeled shapes

there were 300 samples in the size of 120 mesh completely by chance, from every samples were counted that the result of this count shows at the first of successions and the time middle Turonian morphotype group one was conquering and the amount of the morphotype group three was les in the area that this paragraph. Shows the low level of water in area in this time and it is simultaneous with this down calculation time on the umbilical foraminifers structure, and it shows the majority of lip structures an vast orifice without umbilical situation. in the late Turonian the group of morphotype three was increasing in the area that it indicated the proportional increasing of depth in the area and by this time portici structure has been larger and in umbilical structure is born in this unicellular, and in Coniacian time has decreased the amount of morphotype three in the area again and the members of morphotype group one increased with the lip structure in the area again and during Coniacian to Santonian the members of morphotype group 3(M3) with association of tegilla shapes increase in the area for another time and in Santonian time, sea water shows a vacillation mood in the above-mentioned section (Fig3).

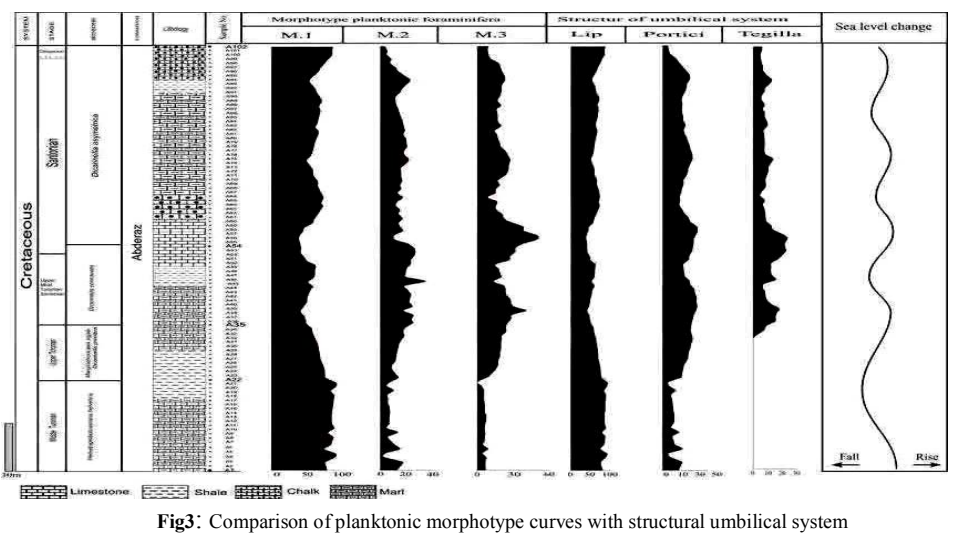

One of the main aim of this paper is that according to the evolution chart of caron (Caron and Homewood, 1983), the primary shapes was coming from Jurassic foraminifers evolution with a vast orifice that lead to the border of the sell that the orifices of this animals are covered by a partial structure called lip, and finally the evolution of these unicellular change to its ancestors and covered by a complete plate called tegilla. These animals live in more depths area compare to its ancestors and the conclusions indicate that the created structures in this unicellular helps with find it compatibility in this animals by the depth they have lived. it seems by swelling the water planktonic foraminifers have some created structure changes in there shells for compatibility with new depths that the alteration trend is like umbilical part of shell compacting with completing a covered plate of the umbilical part that is changed from lip structure to tegilla structure. This created trend leads to decreasing the surface to volume ratio in this unicellular and it causes that the new generation could live in depths that this trend is according to Pascal low and doesn't seem that the created alteration arise from changing nourishing or reproduction way(Fig4)( Fischer and Arthur,1977).

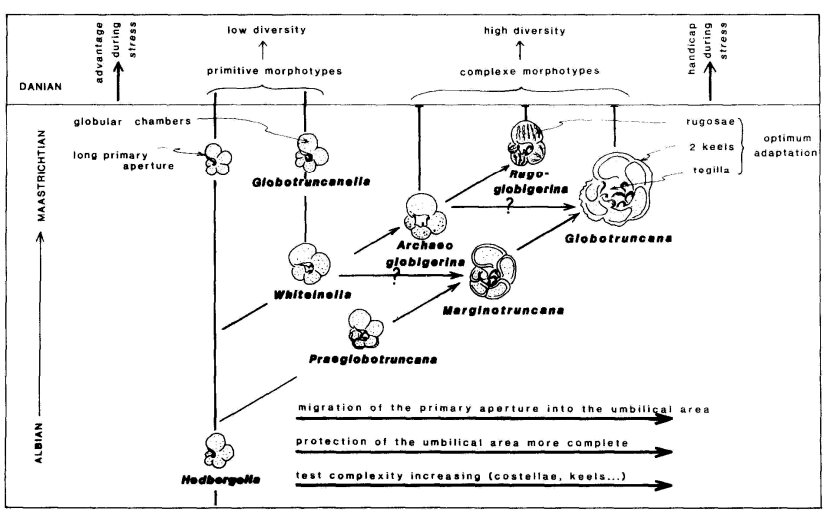

Fig4: Depiction of planktonic foraminifera umbilical system evolution manner in relationship with depth (Fischer and Arthur, 1977).

\section{Discussion}

in the time of middle Turonian simultaneous with subtraction of the percent of morphotype group three that indicates the dwindling of proportional in mentioned section. the structured shapes of lip increases but in the late Turonian that the percent of morphotype three increases that it would indicated the propotional of depth increasing in area and the structured shapes in vicinity has increased and the structured shaped (tegilla) recently has born and in Coniacian time the morphotype group three diminished again and lip shaped increase and in Coniacian -Santonian by increasing the shapes of morphotype three for another time (tegilla) and (portici) became more so that (tegilla) structure became the most in this time. that this affair it is because of the advent of Globotrancana and increasing the number of them in Santonian time but in the late Santonian and the early Campanian by diminishing the percent of morphotype three and increasing morphotype one, the lip shapes became more in area.

Base on this data we can recognize that by increasing the depth of lip structure it changes to a tegilla plate during million years that is unstable structure with one edge. by the continues of this trend the orifice will fine a completely umbilical situation in the end of its evolution that all the mentioned trend leads to decreasing the surface to volume ratio in foraminifers shell that according to Pascal low it can have a grate ability in living longer in more depths compare to their ancestors by the above- mentioned alters. 

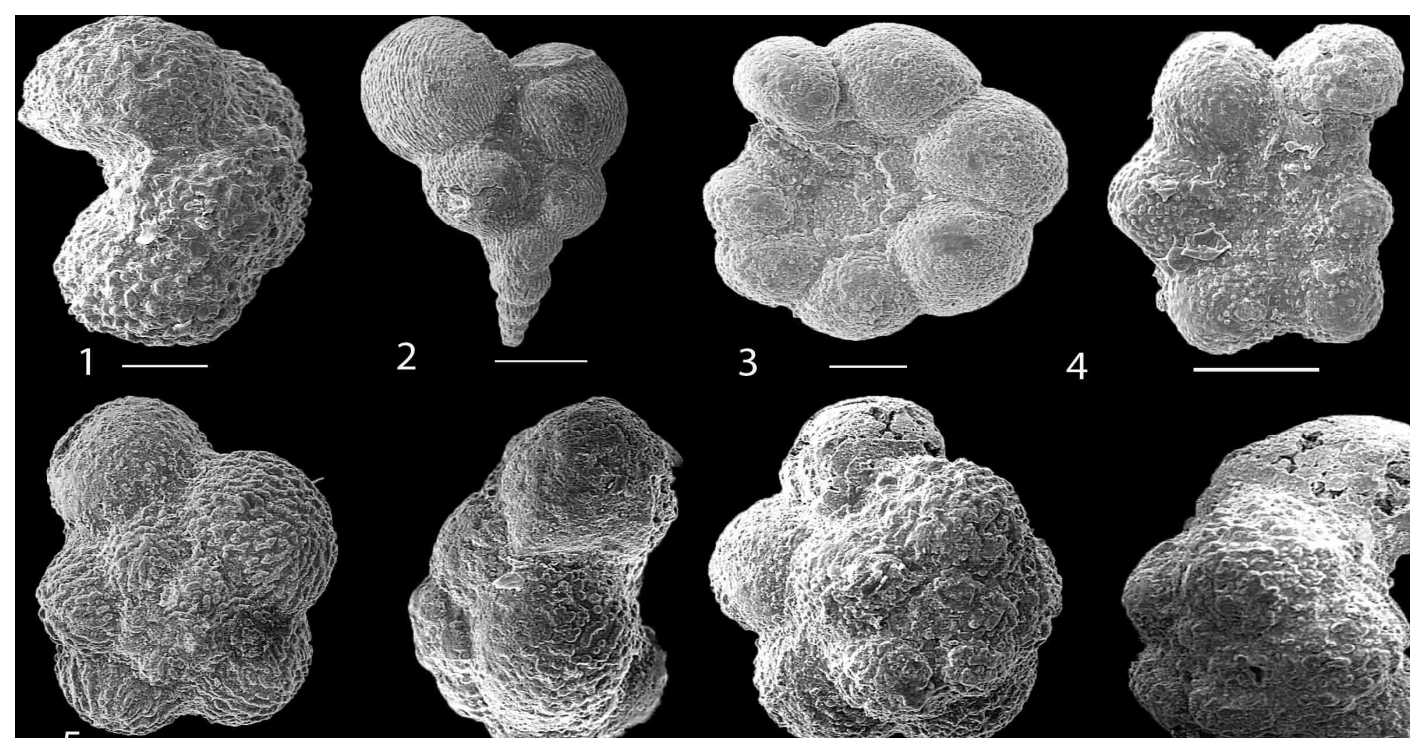

2

3
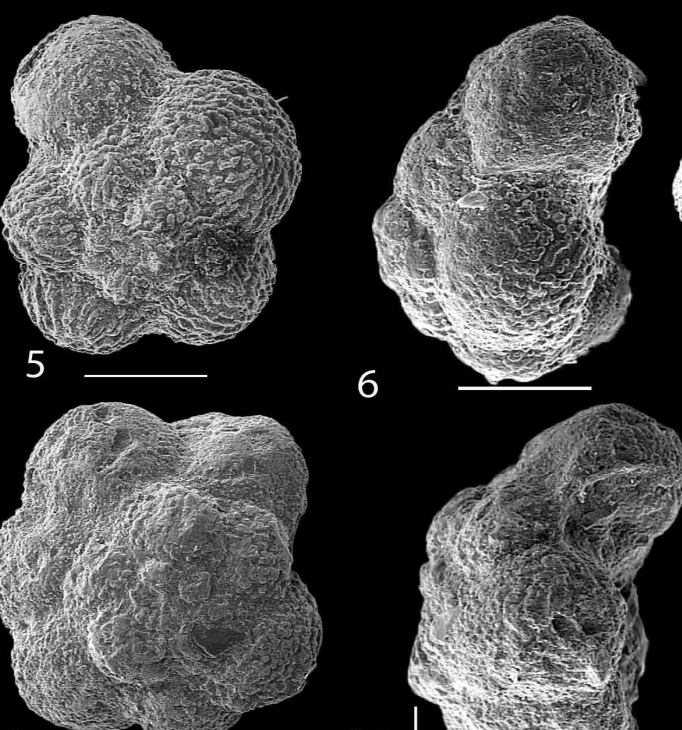

9

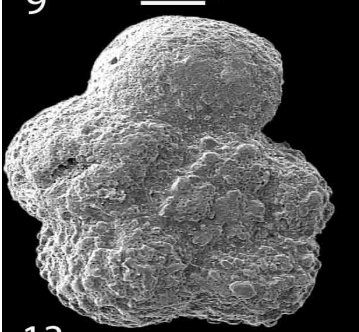

10
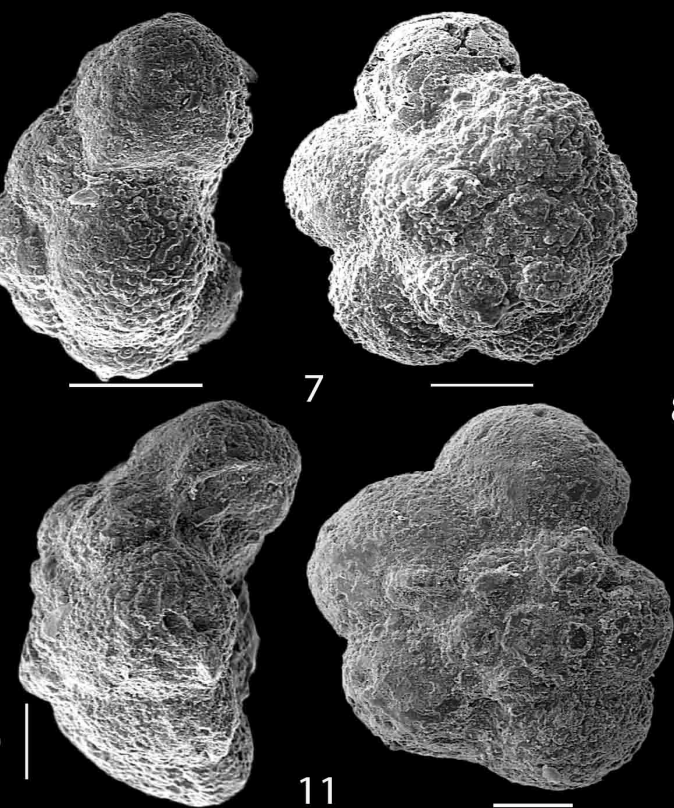

7
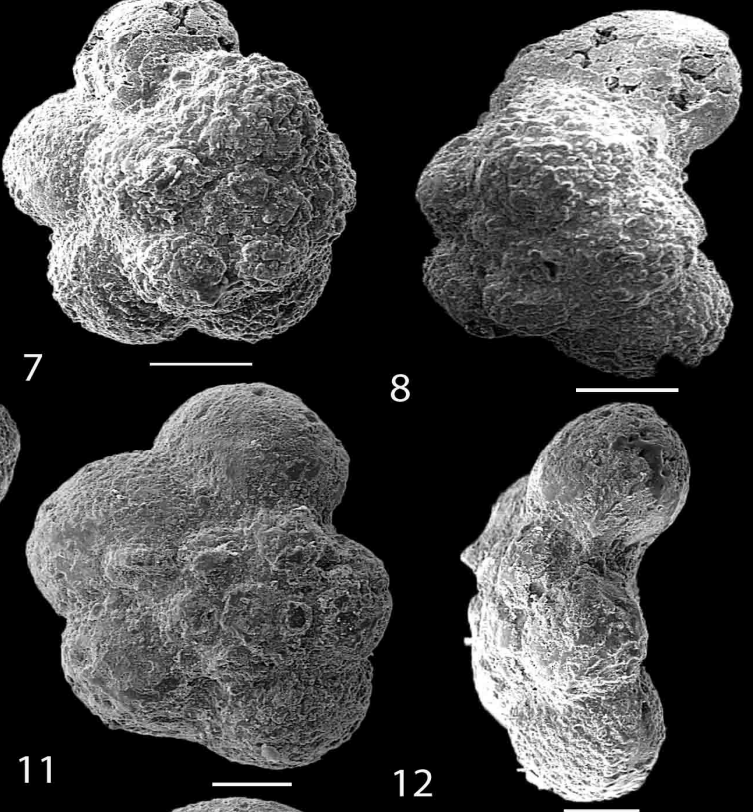

8

11

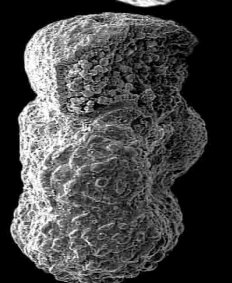

14

17

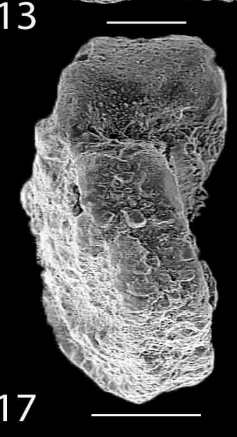

18

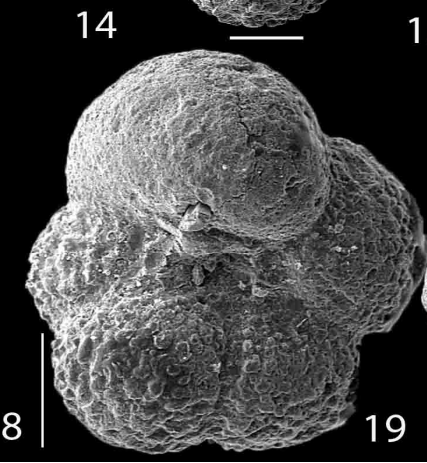

19

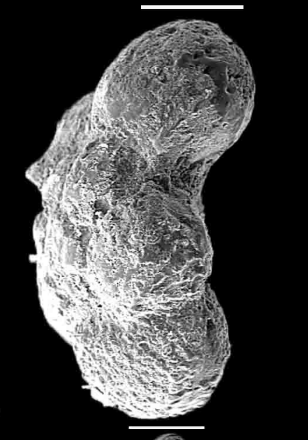

15
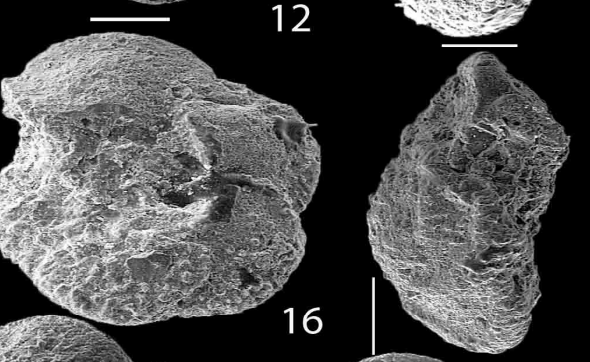

6
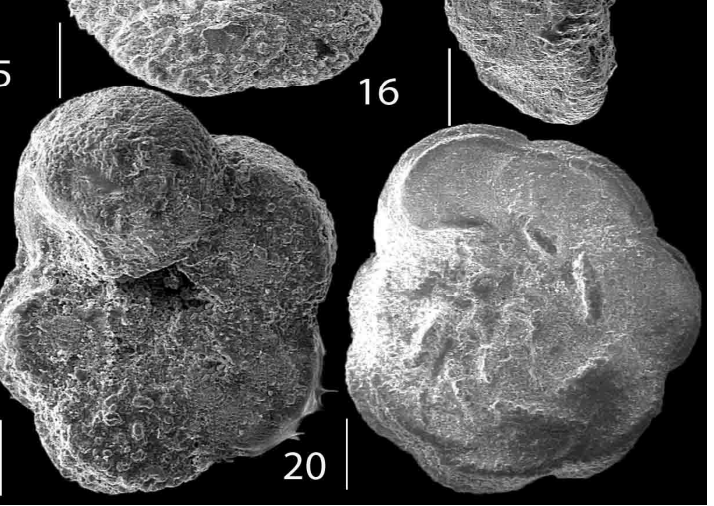

plate1:. Morphotype 1 (1-4): 1; Hedbergella delrioensis, (Sample1). 2;Heterohelix globulosa, (Sample30). 3 ;Globigerinelloides ultramicra , (Sample12). 4; Globigerinelloides alvarezi, (Sample54) . 5; Rugoglobigerina rugosa, (Sample70) . 6; Whiteinella aumalensis (Sample18) . 7-8; Whiteinella paradubia, (Sample30) . 9-10; Praeglobotruncana stephani (Sample26). 11-12; Praeglobotruncana delrioensis, (Sample16). 13-14; Helvetoglobotruncana helvetica (Sample7) .15-16; Marginotruncana sigali, (Sample12). 17; Marginotruncana pseudolinneiana, (Sample53). 18;(lip).umbilical view of Hedbergella delrioensis, (Sample1). 19;(portici). umbilical view of Dicarinella imbricata, (Sample12). 20;(tegilla). umbilical view of Globotruncana arca, (Sample53).all Samples have $100 \mu \mathrm{m}$ scale bar. 


\section{References}

Be,A,W.H,.An econlogical,zoogeographical \& taxonomic review of recent planktonic foraminifera. In:Ramsay, A.T.S.(Editor) Oceanic micropalaeontology, I, 1-100, (1977).

Caron, M., Homewood, P. Evolution of early planktic foraminifers. Mar. Micropaleontology. 7, 435-462.( 1983).

Eicher, D.L.,. Cenomanian \& Turonian planktonic foraminifera from the Western Interior of the United States. In: Bronni- mann, P., Renz, H.H. (Eds.), Proceedings of the First International Conference on Planktonic Microfossils, vol. 2. E.J. Brill, Leiden, pp. 163-174, (1969a).

Eicher,D.l. Cenomanian Turonian plankton foraminifera from the western interior of the United State. In: Bronnimann, P \& Renz., H.H (Editors) proceeding of the First International Conference on planktonic Microfossils, 2, 163-174. (1969b).

Eicher, D.L. \& Worstell, P. Cenomanian \& Turonian, foraminifera from the Great Plains, United States. Micropaleontology, 16, 296-324. (1970).

Fischer, R.G. and Arthur, M.A.. Secular variationsin the pelagic realm. SEPM, Spec. Publ., 25: 19-50. (1977).

Hart,M.B., The recognition of Mid-cretaceous sea level changes by means of foraminifera. Cretaceous Research, I, 289-297. (1980a).

Hart,M. B.. A water depth model for the evolution of the planktonic foraminifera. Nature, 286,252-254. (1980b).

Keller, G., , The Cretaceous-Tertiary Mass extinction in planktonic foraminifera:Biotic constrains for catastrophe theories, in: Macleod,N., \& G.Keller,Cretaceous-Tertiary mass extions:Biotic \& environmental changes,p.49-83, (1999).

Loeblich, A. R., JR., \& Tappan, Helen. Foraminifera from the type Kiowa Shale, Lower Cretaceous of Kansas. Kansas, Univ., Pal. Contr., no. 6 (Protozoa art. 3), pp. 1-1 5, pls. 1-2,(1950).

Loeblich A., Tappan H. Foraminiferal genera and their classification; Van Nostrand Reinhold Company, 970pp. 847 plates, (1988).

Nederbragt A.J. Maastrichtian Heterohelicidae (planktonic foraminifera) from the North West Atlantic. Micropaleontology, 8: 183-206 (1990).

Premoli Silva, I., Sliter, W.V.,. Cretaceous paleoceanography: evidence from planktonic foraminiferal evolution. Geology. Soc Am. Spec. Pap., vol. 332, pp. 301-328. (1999).

Robaszynski F., Caron M. Foraminifères planctoniques du Crétacé: commentaire de la zonation Europe-Méditerranée. Bull. Soc. Geol. Fr, 166: 681-692 (1995).

Robaszynski F., Caron M., Gonzales-Donoso J.-M., Wonders A.A.H. and the European Working Group on Planktonic Foraminifera; Atlas of Late Cretaceous globotruncanids; Revista Micropaleontologia, 26(3-4):145-305 (1983-1984).

Sliter. W.V., Upper Cretaceous planktonic foraminiferal zoogeography \&ecology-eastern Pacific margin. Palaeogeography, Palaeoclimatology, Palaeoecology,v12,p.15-31,(1972).

Wonders , A. A.. Middle \& late Cretaceous planktonic Foraminifera of the western Mediterranean area. Utrecht Micropaleontology Bulletin, 24, $1-158,(1980)$. 